\title{
Aspectos reprodutivos e dieta alimentar dos ninhegos de Rhinoptynx clamator (Aves: Strigidae) no campus Marco Zero da Universidade Federal do Amapá, Macapá-AP
}

\author{
Kurazo Mateus Okada AGUIAR ${ }^{1}$, Rafael Homobono NAIFF ${ }^{1}$
}

RESUMO

Este trabalho tem como objetivo relatar os aspectos comportamentais de nidificação, alimentação e desenvolvimento dos ninhegos de Rhinoptynx clamator (Strigidae) em um fragmento florestal no Campus Marco Zero da Universidade Federal do Amapá. Apenas um ninho foi encontrado, no solo e na base de um tucumã Astrocaryum oleatum. Três ovos brancos com manchas marrons foram observados, cuja medida foi de 41 x $35 \mathrm{~mm}$ em média. A incubação durou 28 dias e foi efetuada pela fêmea, e o último filhote a nascer viveu apenas dois dias. Os filhotes sobreviventes foram medidos durante o seu desenvolvimento. Durante a estação reprodutiva foram coletadas algumas pelotas de regurgitação, sendo encontrados três tipos de vertebrados: Rattus sp., Micoureus cf. regina e Columbina talpacoti.

PALAVRAS-CHAVE: Rhinoptynx clamator, Reprodução, Amapá.

\section{Nesting and diet of Rhinoptynx clamator (Aves: Strigidae) from Campus Marco Zero da Universidade Federal do Amapá, Macapá-AP}

\section{ABSTRACT}

We report nesting behavior, feeding and development of nestling of Rhinoptynx clamator (Strigidae) in a forest fragment on Campus Marco Zero of Universidade Federal do Amapá. The nest was located on the ground, close to a palm Astrocaryum oleatum and three eggs were observed. These eggs were white whit brown spots and measured $41 \times 35$ mm in average. Incubation was made by female and lasted 28 days and the last owlet died two days after born. The remaining birds were measured during its development. Feeding items includes Rattus sp., Micoureus cf. regina and Columbina talpacoti.

KEYWORDS: Rhinoptynx clamator, Nest, Amapá.

1 Pesquisador voluntário, Laboratório de zoologia - IEPA. Instituto de Pesquisas Científicas e Tecnológicas do Estado do Amapá (IEPA), CPZG. Rod. JK, Km 10, s/n, Macapá AP 68900-005. E-mail: kurazookada@ig.com.br 


\section{INTRODUÇÃO}

A Família Strigidae é distribuída por todos os continentes com exceção da Antártica, totalizando 146 espécies no Mundo (Sick, 1997), destas 22 ocorrem no Brasil (CBRO 2006). O mocho orelhudo (Rhinoptynx clamator, também conhecido como Asio clamator ou Pseudoscops clamator), distribui-se do sul do México até o sul da América do sul, estendendo-se por grande parte da Zona Tropical e Subtropical da América do Sul (Martinez et al., 1996; Sick, 1997; Höfling \& Camargo, 2002; Sigrist, 2006).

Há sérios problemas em determinar a real distribuição de R. clamator no Brasil, principalmente na região Norte, onde algumas literaturas não relatam a distribuição desta espécie para o estado do Amapá (Höfling \& Camargo, 2002). A atualização destes dados de distribuição devem ser constantes devido ao fato de sua distribuição ser expandida pelo processo de desmatamento (Sigrist, 2006).

São aves tímidas, de hábito crepuscular-noturno e com audição bem desenvolvida, plumagem extremamente macia, de vôo silencioso (Sick, 1997; Sigrist, 2006). É relativamente comum em paisagens abertas com arvoredo, Cerrado, Caatinga e até dentro de cidades, desde que haja arborização suficiente (Sick, 1997; Höfling \& Camargo, 2002); alimentando-se de roedores, marsupiais, lagartos e anfíbios (Martinez et al., 1996; Sick, 1997; Novaes \& Lima, 1998; Höfling \& Camargo, 2002; Sigrist, 2006).

Este trabalho tem como objetivo relatar os aspectos comportamentais de nidificação, alimentação e desenvolvimento dos ninhegos de $R$. clamator (Strigidae) em um fragmento florestal no Campus da Universidade Federal do Amapá.

\section{MATERIAL E MÉTODOS}

As observaçôes sobre os aspectos da biologia reprodutiva e dieta alimentar do mocho orelhudo foram realizados em um fragmento florestal localizado no Campus Marco Zero da Universidade Federal do Amapá.

O Campus possui uma área de $906.722,45 \mathrm{~m}^{2}$ (Figura 1), o clima predominante corresponde ao clima de feição Equatorial, com temperaturas médias que variam de $25^{\circ}$ a $30^{\circ}$ $\mathrm{C}$, enquanto que, em seu regime de chuvas, o Estado apresenta índices pluviométricos superior a $2.500 \mathrm{~mm}$ anuais (Ab'Saber, 1977). A formação vegetal é caracterizada pela vegetação de Cerrado com quatro fragmentos florestais não interligados, capoeiras e capinzal na porção Norte. A área está sobre forte impacto humano, sendo limitada ao norte pelo bairro Jardim Marco Zero, a oeste pelo bairro Universidade, ao sul pelo Conjunto da Embrapa e a leste pela rodovia JK.

As observações foram realizadas entre os meses de agosto a novembro de 2003, que corresponde ao período de seca

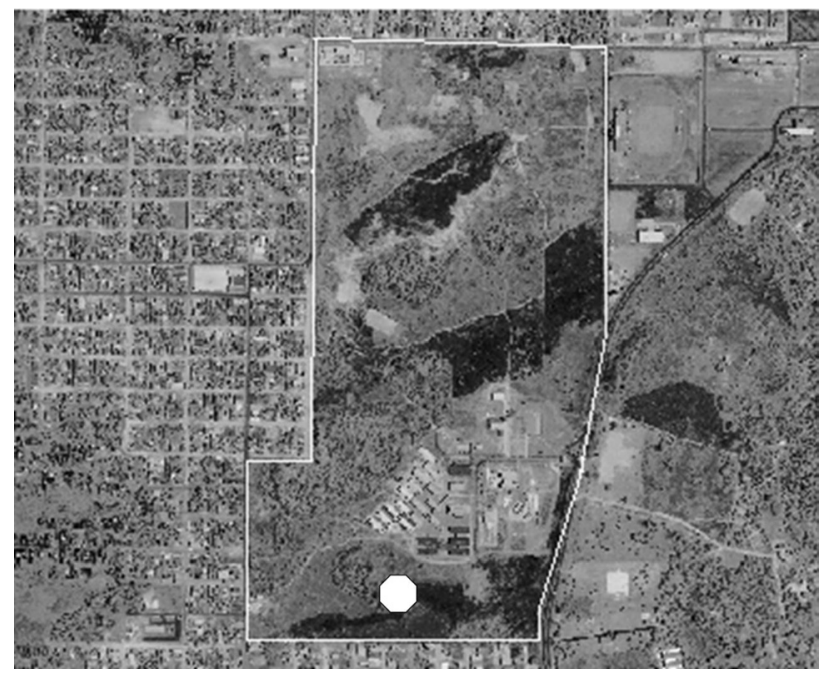

Figura 1 - Área de estudo com a localização (círculo branco) do ninho de Rhinoptynx clamator, no Campus Marco Zero da Universidade Federal do Amapá/AP (Fonte: SEMA-Secretaria Estadual do Meio Ambiente).

na região. Foram utilizados um abrigo artificial camuflado e binóculos $(10 \times 25 \mathrm{~mm}$ e $10 \times 50 \mathrm{~mm})$, com visitaçôes diárias diurnas para verificar o estado dos ninhegos e fazer coleta dos dados morfométricos, localização de pernoite quando os mesmos não dormiam mais no ninho e para coletar pelotas regurgitadas; e noturnas três vezes por semana para registrar o comportamento dos filhotes.

Para analisar o desenvolvimento dos ninhegos foram tomadas às medidas do comprimento do tarso (da base do tarso até o início dos artelhos), comprimento do cúlmen (com cera, até a ponta da maxila), comprimento da asa fechada (do punho até a ponta da rêmige mais longa) e do comprimento do dedo médio. Para os dados sobre a alimentação durante a estação reprodutiva foram coletadas algumas pelotas dentro do ninho e embaixo dos poleiros dos pais. As pelotas coletadas foram armazenadas em sacos plásticos tipo "zip" e depois levados para o laboratório de zoologia da Universidade. O material foi separado em solução de $\mathrm{NaOH}$ a $10 \%$ por três horas para separação do conteúdo, e o material identificado o auxílio de lupa (modelo 106/WF10X - LF), e seus itens identificados por um especialista do Instituto de Pesquisas Cientificas e Tecnológicas do Estado do Amapá-IEPA e bibliografia especifica (Einseberg, 1989; Emmons \& Feer, 1997).

\section{RESULTADOS}

O ninho de $R$. clamator foi encontrado no dia 25 de agosto de $2003 \mathrm{em}$ um fragmento florestal de aproximadamente 400 $\mathrm{m}$ de comprimento por $30 \mathrm{~m}$ de largura, com sub-bosque iluminado e habitado por capins. 
O ninho foi construído no solo na base de um tucumã, Astrocaryum aculeatum (Palmaceae), forrado com poucos capins e alguns gravetos, medindo $31,40 \mathrm{~cm}$ de diâmetro.

Durante o período de setembro (entre os dias 01 e 06) foram postos três ovos com médias de $41 \times 35 \mathrm{~mm}$, de coloração branca e com algumas manchas marrons. No período de incubação, que durou 28 dias, a fêmea sempre estava acompanhada do macho, que ficava empoleirado em uma árvore próxima do ninho, aproximadamente a $6 \mathrm{~m}$.

No dia 29 de setembro apenas um dos três ovos eclodiu, os demais eclodiram nos dias 03 e 05 de outubro, sendo que após dois dias o ninhego mais novo foi encontrado morto. Nascem de olhos fechados e cobertos por uma fina plumagem branca. A mãe permanece no ninho dormindo e protegendo os ninhegos por um período curto de oito dias até abrirem os olhos. Com 13 dias de vida nota-se a presença dos canhōes das rêmiges e retrizes, e também a formação do disco facial. Com 20 dias de vida saem do ninho ao anoitecer e ficam vocalizando e exercitando as asas.

A postura de intimidação foi presenciada com oito dias de vida, e consiste em erguer as asas em posição vertical e com freqüentes estalos de bico. Com 25 dias de vida começam a aparecer os tufos de penas que caracterizam o nome vernáculo da espécie, "as orelhas". A partir do $26^{\circ}$ dia de vida, os ninhegos já não dormem no ninho, ficando o mais velho empoleirado em um arbusto a uma altura de $30 \mathrm{~cm}$, enquanto o mais novo escondido de baixo da vegetação rasteira a uns cinco metros do ninho. A partir desta idade os ninhegos dormem em lugar diferente dos dias anteriores e sempre acompanhados dos pais.

$\mathrm{Na}$ manhã do dia $1^{\circ}$ de novembro, com aproximadamente um mês de vida, já bem emplumados, porém sem haverem aprendido a voar, o ninhego mais velho foi encontrado em uma árvore de pequeno porte a $3 \mathrm{~m}$ de altura, e o outro a 2 $\mathrm{m}$ de altura. Na noite do dia 06 de novembro presenciamos os primeiros vôos rasantes do filho mais velho, enquanto que o mais novo não foi localizado.
Durante o período de observação dos ninhegos, foram feitas medições do tarso, asa, cúlmen e do dedo médio. Os dados demonstram desenvolvimento rápido dos filhotes desta espécie os quais, por exemplo, triplicaram em tamanho de tarso em um intervalo de 25 dias (Tabela 1).

Foram coletadas pelotas regurgitadas pelos ninhegos e adultos dentro do ninho e embaixo dos poleiros. As análises das pelotas mostraram que há uma maior frequiência na capturar de roedores (Rattus sp.) devido, possivelmente, ao acumulo de lixo doméstico jogados pelos moradores do entorno da área. Foram encontrados também um crânio de marsupial (Micoureus cf. regina) e penas de rolinha (Columbina talpacoti).

\section{DISCUSSÃO}

A estação reprodutiva de $R$. clamator ocorreu de setembro a novembro de 2003, que corresponde à estação de seca. Bledinger et al. (1987), De La Peña (1987) e Martinez et al. (1996) consideram que a reprodução de $R$. clamator é outono-invernal.

A espécie em estudo nidificou no solo, na base de uma palmeira, assim como em ninhos relatados na literatura (De La Pena, 1987; Canevari et al., 1991; Martinez et al., 1996). Mas outros autores relatam que esta espécie pode nidificar em árvores (Bledinger et al., 1987), e também, que espécies do mesmo Gênero (Rhinoptynx $=$ Asio $)$ podem utilizar ninhos abandonados de aves de grande porte, como de gavióes e garças (Sigrist, 2006).

Houve a postura e incubação de três ovos, com média de $41,5 \times 35$ mm de coloração branca com manchas marrons. Alguns autores citam a postura de dois a quatro ovos de cor branca (Canevari et al., 1991; Novaes \& Lima, 1998; Höfling \& Camargo, 2002).

A incubação durou 28 dias sendo muito similar aos resultados de estudos feitos por Martinez et al. (1996) na província de Buenos Aires, assim como em outras citações

Tabela 1 - Medidas em milímetros dos filhotes de Rhinoptynx clamator em um fragmento florestal no Campus da Universidade Federal do Amapá. F1= filhote $1, \mathrm{~F} 2=$ filhote $2, \mathrm{M}=$ média, $\mathrm{DP}=$ Desvio Padrão.

\begin{tabular}{llllllllll}
\hline & \multicolumn{3}{l}{$11 / 10 / 2003$} & \multicolumn{3}{c}{$24 / 10 / 2003$} & \multicolumn{3}{c}{$04 / 11 / 2003$} \\
\hline & F1 & F2 & M \pm DP & F1 & F2 & M \pm DP & F1 & F2 & M \pm DP \\
Tarso & 30 & 21 & $25 \pm 4.5$ & 50 & 40 & $45 \pm 5$ & 100 & 95 & $97 \pm 2.5$ \\
Dedo médio & 27 & 25 & $26 \pm 1$ & 55 & 45 & $50 \pm 5$ & 57 & 50 & $53 \pm 3.5$ \\
Cúlmen & 24 & 20 & $22 \pm 2$ & 32 & 33 & $32 \pm 0.5$ & 35 & 35 & - \\
Asa & 14 & 90 & $115 \pm 25$ & 230 & 220 & $225 \pm 0.5$ & 310 & 300 & $305 \pm 5$ \\
\hline
\end{tabular}


na literatura (Bledinger et al., 1987; De La Pena, 1987; Sick, 1997; Novaes \& Lima, 1998; Höfling \& Camargo, 2002), e também para outras espécies do mesmo Gênero (Rhinoptynx = Asio), Asio flammeus e Asio otus que pode variar de 25 a 30 dias (Holt et al., 1992; Maples et al., 1995).

$\mathrm{O}$ rápido crescimento dos filhotes, que neste estudo foi amostrado por um intervalo de 21 dias (tempo corresponde entre o primeiro e o último dia de obtenção dos dados morfológicos), comparados com os dados obtidos por Martinez et al. (1996), que teve um intervalo de 22 dias, mostraram que a amplitude de crescimento foi maior neste estudo. A diferença observada entre estes dois estudos pode ser explicada pela diferença no número de crias, três no estudo feito por Martinez et al. (1996) e dois neste estudo, e pela disponibilidade de alimento e freqüência na alimentação.

$\mathrm{O}$ aprendizado da vocalização iniciou-se nos primeiros dias de vida assim como a postura de intimidação, com 13 dias começam a aparecer os canhōes das rêmiges e retrizes e o disco facial, com 25 dias os tufos de penas da cabeça "orelhas" já são visíveis, com 26 dias a prole abandona o ninho dormindo em local diferente a cada dia e com e com 38 dias já podem voar, dados similares com os obtidos por Martinez et al. (1996).

A formação de pelotas (vômitos, chamados também de egagrópilas, ejeção de material após a ingestão) possibilitada por ossos, espinhos, penas, pelos ou quitina, é uma necessidade vital para essas aves e podem fornecer importantes dados sobre sua alimentação (Sick, 1997). Nas pelotas analisadas foram identificados três tipos presas: rato (Rattus $\mathrm{sp}$ ), marsupial (Microureus cf. regina) e rolinha (Columbina talpacoti), com o predomínio de ratos. Martinez et al. (1996) encontrou quatro espécies de roedores em sua dieta (Reithrodon auritus, Colomys sp., Holochilus brasiliensis e Rattus sp.) e duas espécies de aves (Zenaida auriculata e Carduelis magellanica). Podem, também, se alimentar de morcegos, lagartos e anfíbios (Martinez et al., 1996; Sick, 1997; Novaes \& Lima, 1998; Höfling \& Camargo, 2002; Sigrist, 2006).

\section{AGRADECIMENTOS}

Aos Prof. MSc. Carlos Eduardo Costa Campos e MSc. Andréa Soares Araújo da Universidade Federal do Amapá pelo projeto de pesquisa realizado no Campus. A MSc. Claudia Silva (Instituto de Pesquisas Cientificas e Tecnológicas do Estado do Amapá - IEPA) e Elizandra Matos Cardoso da Silva pela identificação dos roedores e marsupiais, e ao MSc. Luiz Antônio Coltro Júnior (IEPA) pela criteriosa revisão e sugestão de melhoras no texto.

\section{BIBLIOGRAFIA CITADA}

Ab'Saber, A.N. 1977. Os Domínios morfoclimáticos da América do Sul. Primeira Aproximação. Geomorfologia, 52:1-21.

Bledinger, P.; De Luca, E.; Saggese, M. 1987. Nidificación otoñoinvernal del Lechuzón Orejudo. Nuestras Aves, 5:19.

Canevari, M.; Saggese P.; Carrizo, G.R.; Harris, G.; Rodriguez-Mata, J.; Straneck, R. 1991. Nueva guia de las aves Argentinas. Tomos Iy II. Buenos Aires.

CBRO - Comitê Brasileiro de Registros Ornitológicos. 2006. Listas das Aves do Brasil. Versão 10/2/2006. Disponível em http://www. cbro.org.br. Acesso em junho de 2007.

De La Pena, M.R. 1987. Nidos y huevos de aves Argentinas. Santa $F e ́$.

Einseberg, J.F. 1989. Mammals of the Neotropics, Vol. 1, The Northern Neotropics: Panamá, Colombia, Suriname, French Guiana. The University of Chicago Press. Chicago and London. 449pp.

Emmos, L.; Feer, F. 1997. Neotropical rainforest mammals: a fild guide. Second Edition. The University of Chicago Press, Chicago. 307 pp.

Höfling, E.; Camargo H.F.A. 2002. Aves no Campus. $3^{\circ}$ ed. São Paulo. Ed. da Universidade de São Paulo, Instituto de Biociências. 168pp.

Holt, D.W.; Melvin, S.M.; Steele, B. 1992. Nesting growth rates of Short-eared Owls. Wilson Bulletin, 104: 326-333.

Maples, M.T.; Holt, D.W.; Campbell, R.W. 1995. Ground-nesting Long-eared owls. . Wilson Bulletin, 107: 563-565.

Martinez, M.M.; Isacch, J.P.; Donatti, F. 1996. Aspectos de la distribucion y biologia reproductiva de Asio Clamator em la província de Buenos Aires, Argentina. Ornitologia Neotropical, 7: $157-161$.

Novaes, F.C.; Lima, M.F.C. 1998. Aves da Grande Belém. 415pp.

Sick, H. 1997. Ornitologia Brasileira. Ed. Nova Fronteira, 912pp.

Sigrist ,T. 2006. Aves do Brasil: uma visão artística. Ed. Fosfetil, $672 \mathrm{pp}$.

Recebido em 28/03/2008

Aceito em 11/11/2008 